\title{
A questão das origens das línguas germânicas na história dos estudos da linguagem
}

DOI: http://dx.doi.org/10.21165/el.v49i2.2738

\section{Rogério Ferreira da Nóbrega'}

\section{Resumo}

O agrupamento das línguas germânicas é um assunto que ocupou vários estudiosos desde o período pré-científico que precede o século XIX. Tal prática teve motivações diversas, a depender do período específico da história dos estudos da linguagem. Sua motivação pode ser a de estabelecer uma subdivisão de línguas a partir de um estágio ainda pré-literário ou reconstruir proto-línguas desses estágios. O objetivo deste artigo é fornecer uma visão geral da questão das origens das línguas germânicas na história dos estudos da linguagem. Primeiramente, discutimos quatro períodos distintos dessa história. Buscamos, então, demonstrar como as abordagens adotadas face ao problema nos diferentes períodos refletem o "Modelo de Descontinuidade-vs.-Continuidade" proposto por Koerner (1989b). Nosso estudo demonstra que a geografia linguística, entre outras tradições, também desempenhou um papel importante nas investigações, embora outras tradições tenham sido os paradigmas dominantes nos séculos XIX e XX.

Palavras-chave: línguas germânicas; agrupamento; historiografia linguística; periodização.

1 Universidade de São Paulo (USP), São Paulo, São Paulo, Brasil; rogerio.nobrega@usp.br; https://orcid.org/0000-0001-9684-1952 


\title{
The issue of the origins of the Germanic languages in the history of the study of language
}

\begin{abstract}
The grouping of the Germanic languages is a subject that has occupied a number of scholars since the pre-scientific period that precedes the 19th century. Such practice has had diverse motivations, depending on the specific period of the history of the study of language. Its motivation may be to establish a subdivision of languages from a still preliterary stage or to reconstruct proto-languages of these stages. The aim of this paper is to give an overview of the issue of the origins of the Germanic languages in the history of the study of language. First, we discuss four distinct periods of the history of the language sciences. We then try to demonstrate how the approaches to the problem adopted in the different periods reflect the "Discontinuity-vs.-Continuity Model" proposed by Koerner (1989b). Our study shows that the linguistic geography, among other traditions, also played a major role in the investigations, although other traditions were the dominant paradigms in the 19th and 20th centuries.
\end{abstract}

Keywords: Germanic languages; grouping; linguistic historiography; periodisation.

\section{Introdução}

Aquele que se interessar pelo problema das origens das línguas certamente deparar-se-á com propostas de estabelecimento de relações genéticas entre as línguas, tentativas de agrupá-las em famílias ou reconstruir seus estágios anteriores na forma de protolínguas. No caso específico das línguas germânicas, esse cenário não foi diferente. As primeiras classificações de povos germânicos de que temos registros não tiveram critérios linguísticos para sua consecução: na Germania (1999 [98 AD]) de Tácito, por exemplo, a divisão dos germanos se dá pela nomeação de diferentes grupos tribais. Outras fontes documentais sobre tribos germânicas, de seus movimentos migratórios, locais de estabelecimento e de informações etnográficas a seu respeito são os escritos de Júlio César (100 a.C-44 a.C.), Estrabão (63 a.C.-23 d.C.), Plínio, o Velho (23-79), Claudio Ptolomeu (100-170), Jordanes (séc. VI), Gregório de Tours (538-594), Beda Venerabilis (673-735), Paulo, o Diácono (720-799) e Viduquindo de Corvey (925 -980), muito embora, quando comparadas, tais fontes apresentem informações que contradizem umas às outras e, portanto, devem ser consideradas com cautela (cf. KUFNER, 1972b).

Relatos de historiadores não foram os únicos critérios utilizados para a divisão de tribos germânicas. No que tange às tentativas da parte de filólogos e linguistas, a classificação feita por Johann Christoph Adelung (1732-1806), em sua Mithridates oder allgemeine Sprachenkunde ("Mitrídates, ou a ciência geral das línguas", 1809), foi uma das primeiras a sugerirem uma divisão bipartite das línguas germânicas. Antes, Friedrich Carl Fulda 
(1724-1788) fizera uma divisão das línguas germânicas em um grupo "alto" e outro "baixo" (FULDA, 1776, p. 3-4). Ambas as propostas foram realizadas em um momento que precede à era científica do século $X I X$, e, desde então, inúmeras outras se seguiram ao longo de mais de dois séculos de estudos da linguagem, e, assim, o agrupamento das línguas germânicas foi objeto de investigação das mais variadas tradições de pesquisa.

A história das ciências da linguagem do século XIX e da metade do XX pode ser dividida em, ao menos, quatro momentos distintos que contemplam o surgimento da linguística histórico-comparativa, na Alemanha do início do século XIX, passando por sua consolidação e por seu desenvolvimento na Europa, até a emergência dos estruturalismos estadunidense e europeu, já no século XX. Nesses períodos, inúmeras tentativas de agrupamento das línguas germânicas foram realizadas no âmbito das diferentes tradições de pesquisa então vigentes.

No presente trabalho, objetivamos discutir os eventos intelectuais e o clima de opinião de cada um dos quatro momentos, a fim de situar a questão da origem das línguas germânicas em seus respectivos contextos. Nessa cronologia se inclui a geografia linguística (Sprachgeographie), que representa uma longa e continuada tradição de pesquisa, que pode ser entendida como "secundária", dentro de um modelo historiográfico que descreva a dinâmica de continuidades e descontinuidades de correntes centrais e secundárias na história da linguística (cf. KOERNER, 1989b). Guardadas as devidas proporções, ao menos no que diz respeito ao protagonismo assumido por dialetólogos no debate sobre 0 agrupamento das línguas germânicas em certos momentos do século XX, as importantes contribuições da dialetologia, termo aqui empregado com o mesmo sentido de geografia linguística, colocam-na em situação análoga à condição de cinosura da subdisciplina (HYMES, 1974). O período pré-científico anterior ao século XIX será discutido de maneira sintética, e o pós-estruturalista, quando também foram empreendidas tentativas de agrupamento das línguas germânicas, não será aqui analisado.

\section{Algumas considerações teóricas}

Para um trabalho que se pretenda historiográfıco, a periodização é uma etapa de grande relevância tanto para o nível heurístico, isto é, de levantamento e coleta de dados, como para o nível hermenêutico ou interpretativo (SWIGGERS, 2004). A periodização que esboçaremos adiante é, em grande medida, bastante simplificada. De fato, tanto os períodos em si como a transição entre eles são marcados por uma dinâmica muito mais complexa do que se possa deduzir desta breve discussão, tendo em vista que o desenvolvimento das ciências da linguagem envolvenão apenas eventos intradisciplinares, mas também inúmeros acontecimentos extradisciplinares. 
Considerando as realidades sociais subjacentes às comunidades científicas e suas práticas, Hymes (1974) discorre sobre as diferentes tradições de pesquisa que disputam a condição de "cinosura", ou seja, que almejam à centralidade da disciplina, enquanto Murray (1994) desenvolve uma teoria sobre a formação de grupos (clusters) científicos e a retórica que adotam, a depender de se, entre outros fatores, o acesso ao reconhecimento (publicação) Ihes é concedido ou recusado. Se o acesso Ihes é concedido, a retórica será continuísta, se lhes é recusado, será revolucionária, o que também dependerá de outros fatores, como a idade profissional dos envolvidos e o status de sua instituição de origem. Um grupo científico, nos termos de Murray, é bem-sucedido quando alcança a condição de grupo de especialidade. Para que isso ocorra, três condições devem coexistir: boas ideias, liderança intelectual e liderança organizacional. "Sem todos os três fatores, nenhum grupo científico emergirá. Todos são necessários. Um não é suficiente" (MURRAY, 1994, p. 23, tradução nossa ${ }^{2}$. Os fatores sociais e institucionais se tornam cada vez mais importantes na medida em que nos aproximamos da época moderna (SWIGGERS, 2004).

Apesar de também considerar aspectos sociais, o modelo kuhniano de revoluções científicas $^{3}$ se mostrou inadequado para elucidar o processo de desenvolvimento das ciências da linguagem, em que não houve um paradigma científico que tenha suplantado totalmente seu precedente no que diz respeito à integralidade da disciplina. Dessa forma, a emergência de uma nova tradição central não necessariamente implica o desaparecimento da anterior, podendo haver a coexistência de duas ou mais tradições, como observou Hymes. Para a compreensão de fenômenos históricos como esse, Koerner (1989b) propõe, entre outros, um "Modelo de Descontinuidade-vs.-Continuidade" ("Discontinuity-vs.-Continuity Model"). Esse modelo (ver figura 1) é mais realista para a análise da história das ciências da linguagem, pois contempla não somente a "tradição central" ou a "cinosura" da disciplina em dado momento, mas também tendências novas e antigas, que se estabeleceram ou se mantiveram.

\footnotetext{
2 No original: "Without all three factors, no scientific group will emerge. All are necessary. No one is sufficient".

3 Referimo-nos aqui ao modelo proposto por Thomas Samuel Kuhn (1922-1996), em seu ensaio intitulado The Structure of Scientific Revolutions (1970 [1962]), em que o autor rejeita a ideia de progresso científico mediante acumulação do conhecimento em favor de uma ideia de sucessão de paradigmas.
} 
Figura 1. Modelo de Descontinuidade-vs-Continuidade

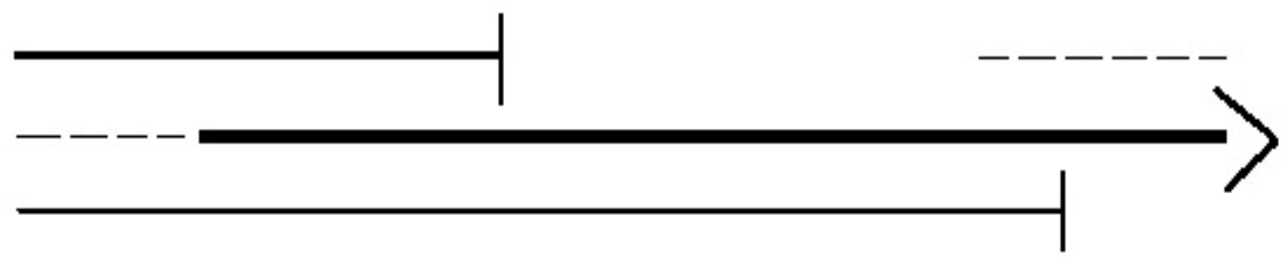

Fonte: Koerner (1989b, p. 53)

Na história da linguística, portanto, o termo "paradigma" não equivale necessariamente a uma hegemonia absoluta no interior de uma disciplina.

\section{Periodização das ciências da linguagem}

Consideraremos em nossa discussão quatro momentos, a saber, aqueles do século XIX distinguidos pelas três gerações que Morpurgo Davies (2014a) chamou de fundadores, consolidadores e desenvolvedores, além de um quarto período, em que se destacaram os estruturalismos estadunidense e europeu. A razão para a delimitação desses períodos não reside no fato de que os estudos sobre a linguagem tenham se iniciado apenas no século XIX. Muito pelo contrário: até o início do século XIX, muitos estudos haviam sido realizados, porém, eram incipientes. Robins (1967, p. 164-165, tradução nossa ${ }^{4}$ ), a esse respeito, faz a seguinte afırmação:

Pode-se falar, com razão, do trabalho histórico do século anterior ao XIX como esporádico, não porque ele necessariamente carecesse de uma visão ou de uma apreciação do que estava envolvido, mas porque as sugestões e pesquisas das pessoas permaneciam, em grande parte, isoladas, e como elas não eram

4 No original: "One can rightly speak of pre-nineteenth-century historical work on languages as sporadic, not because it necessarily lacked insight or an appreciation of what was involved, but because people's suggestions and researches remained largely in isolation, and since they were not taken up and developed by a continuous succession of scholars, each new thinker had little to build on or to react to. This was not so after 1800, when one is brought face to face with a remarkable continuity of scholarship focused on a specialized field of theory and practice, in which generations of men, mostly Germans or scholars from other countries trained in Germany, built up their subject on the basis of what had been done by their predecessors or earlier contemporaries. They might start from where those before them had left off, or they might react against what they had considered errors of fact or misdirections of theory; but the sense of continuity of achievement, leading to a culmination, though not, of course, a stopping point, towards the end of the century, must be regarded both as a tribute to the scholarship of the time and as an inspiration to those looking back today on this remarkable century of successful endeavour". 
retomadas e desenvolvidas por uma sucessão contínua de estudiosos, cada novo pensador tinha pouco em que se basear ou contra que reagir. Isso não foi assim depois de 1800, quando se é defrontado com uma notável continuidade de estudos voltados a um campo de especialidade de teoria e prática, no qual gerações de homens, principalmente alemães ou estudiosos de outros países treinados na Alemanha, construíram sua disciplina com base no que havia sido feito por seus antecessores ou contemporâneos anteriores. Eles podiam começar de onde aqueles antes deles haviam parado ou reagir contra o que consideraram erros de fato ou desvios de teoria; mas o senso de continuidade de êxito, levando a um ponto culminante, embora não, é claro, a um ponto de parada, no final do século, deve ser considerado tanto um tributo aos estudos da época como uma inspiração para aqueles que hoje relembram aquele notável século de empreendimentos bem-sucedidos.

Antes de adentrarmos os quatro momentos propriamente ditos, contextualizemos o século XIX em relação aos fatos e actantes que o antecederam. Para tanto, faz-se necessário abordar alguns dos eventos intelectuais, institucionais e socioculturais mais significativos que caracterizaram aquele período e a transição para o seguinte, quando se desenvolveram as investigações de uma nova filologia.

\section{Os precursores}

A preocupação com a natureza da língua, seus aspectos e sua origem vem de longa data: na época da Renascença, por exemplo, já havia a juntada de documentos, que, mais tarde, serviriam aos estudos comparados das línguas, e Gottfried Wilhelm Leibniz (16461716) já apontava topônimos e nomes de rios como possíveis fontes para os estudos da língua (ROBINS, 1967).

Termos até hoje utilizados, como 'língua mãe', 'família linguística', 'língua irmã' etc. não são novidades do século XIX, e o agrupamento de línguas em famílias era, também, prática reconhecida de outrora, como na Idade Média e no próprio período renascentista (MORPURGO DAVIES, 2014g). Entretanto, foi a redescoberta do sânscrito no ocidente a responsável por dar uma nova direção às investigações. Desde o início das missões jesuítas na Índia já se notavam semelhanças entre o sânscrito e as línguas da Europa, mas a mudança de rumo teria ocorrido somente depois de Sir William Jones (1746-1794) pronunciar o Terceiro Discurso de Aniversário sobre os Hindus, na Sociedade Asiática de Calcutá, em fevereiro de 1786. Reproduzimos aqui um famoso trecho de sua autoria, publicado em 1788, recorrentemente citado em manuais historiográficos e de linguística histórica:

A língua sânscrita, qualquer que seja sua antiguidade, é de uma estrutura maravilhosa; mais perfeita que o grego, mais copiosa do que o latim e mais 
delicadamente refinada que qualquer deles, tendo com ambos, contudo, tanto nas raízes dos verbos como nas formas da gramática, uma afinidade mais forte do que uma que pudesse ter sido produzida por acidente; tão forte, de fato, que nenhum filólogo poderia examinar as três sem crer que tivessem surgido de uma fonte comum, que talvez não exista mais: há uma razão conhecida, embora não tão vigorosa, para supor que tanto o gótico como o celta, ainda que misturados com um idioma muito diferente, tenham a mesma origem do sânscrito; e o persa antigo poderia ser adicionado à mesma família, se esta fosse a ocasião para dificultar qualquer questão relativa às antiguidades da Pérsia. (JONES, 1807, p. 34-35, tradução nossa5).

Não por coincidência, o vigor desse parágrafo confere a Sir William Jones o papel de um dos precursores da linguística do século XIX, ainda que seus principais interesses não fossem puramente linguísticos (MORPURGO DAVIES, 2014b), e tampouco fosse essa ideia propriamente uma novidade.

Em 1808, Karl Wilhelm Friedrich von Schlegel (1772-1829) publica sua obra Über die Sprache und Weisheit der Indier: Ein Beitrag zur Begründung der Alterthumskunde ("Sobre a língua e sabedoria dos indianos: uma contribuição para a fundação da ciência da antiguidade"). Nessa obra, a análise da morfologia prevalece sobre os demais níveis de articulação, e se demonstra a relação existente entre o passado dos persas, indianos, romanos, gregos, egípcios antigos, etíopes, germanos e, mais remotamente, armênios, eslavos e celtas. A língua sânscrita é, então, percebida como superior, de forma que as demais línguas teriam sido derivadas diretamente dela ou de sua antecessora, o que terminou por transformar todas as assunções que se tinha até então sobre a origem das línguas. Ademais, entendiase que as línguas eram sujeitas à degradação, a observar pela deterioração do sistema flexional das línguas que teriam descendido do sânscrito ou de seu ancestral. Schlegel, então, passa a ter elementos para atacar seus antecessores no que concerne à teoria da então suposta monogênese das línguas. De acordo com Morpurgo Davies, um dos êxitos de Schlegel consiste na impressão por ele deixada de que a descoberta do sânscrito dava novos rumos à filologia na Alemanha, o que, inclusive, resultou na criação de novas cátedras sânscritas e no reconhecimento da disciplina em um período de consolidação da própria linguística como disciplina autônoma, somada ao sentimento de nascimento

5 No original: "The Sanscrit language, whatever be its antiquity, is of a wonderful structure; more perfect than the Greek, more copious than the Latin, and more exquisitely refined than either, yet bearing to both of them a stronger affinity, both in the roots of verbs and in the forms of grammar, than could possibly have been produced by accident; so strong indeed, that no philologer could examine them all three, without believing them to have sprung from some common source, which, perhaps, no longer exists: there is a familiar reason, though not quite so forcible, for supposing that both the Gothick and the Celtick, though blended with a very different idiom, had the same origin with the Sanscrit; and the old Persian might be added to the same family, if this were the place for difficulting any question concerning the antiquities of Persia". 
de uma nova Philologie, mais ampla, acadêmica e sistemática, baseada na empiria e não mais limitada a textos isolados. Registre-se que esses são eventos ocorridos no contexto do romantismo alemão, período em que havia um entusiasmo por tempos remotos, pela poesia primitiva e pelo folclore, de forma que o passado deveria ser reconstruído a partir de suas origens no oriente (MORPURGO DAVIES, 2014b). Quanto à taxonomia empregada, o termo "gramática comparativa" (vergleichende Grammatik) teve origem nos estudos de Friedrich Schlegel (ROBINS, 1967), caracterizando, assim, uma inovação terminológica importante.

Em 1818, o dinamarquês Rasmus Kristian Rask (1787-1832) publica sua Undersøgelse om det gamle Nordiske eller Islandske Sprogs Oprindelse ("Investigação sobre a Origem da Antiga Língua Nórdica ou Islandesa"). Ainda de acordo com Morpurgo Davies, seu poder de alcance teria sido prejudicado em virtude de a obra ter sido publicada em língua dinamarquesa e somente após a obra Über das Conjugationssystem der Sanskritsprache in Vergleichung mit jenem der griechischen, lateinischen, persischen und germanischen Sprache ("Sobre o sistema de conjugação da língua sânscrita em comparação com o da língua grega, latina, persa e germânica", 1816), de Franz Bopp (1791-1867). Na seção sobre as "línguas trácias" (i.e., grego e latim), Rask estabelece as correspondências regulares entre $p, t, k$ do latim e $f, p$ e $h$ do gótico, que, mais tarde, viriam a ser conhecidas como "Lei de Grimm". O próprio Jacob Grimm (1785-1863), no prefácio à primeira edição de sua Deutsche Grammatik ("Gramática Germânica", 1818, p. xviii-xix) lamenta a publicação "tardia" da obra de Rask, cujos aspectos não puderam ser incorporados à sua própria gramática, o que terminou por acontecer na segunda edição de sua Deutsche Grammatik (1822), que deu publicidade à referida "lei". Apesar de não incluir análises das línguas orientais, a gramática de cunho descritivo de Rask representa uma primeira tentativa comparativista das línguas indo-europeias, e seu interesse em retenções e inovações linguísticas Ihe conferem tal-qualmente um caráter histórico. A depender da abordagem, Rask pode ser considerado precursor ou fundador (MORPURGO DAVIES, 2014c).

\section{Os fundadores}

Franz Bopp teve como base o trabalho de Schlegel, o que nos leva ao questionamento sobre se o recorte referente ao início da linguística histórico-comparativa não poderia ser o ano da publicação de Über die Sprache und Weisheit der Indier (1808), de Schlegel. Koerner (1999a, p. 89, tradução nossa6), faz a seguinte declaração acerca desse período:

6 No original: "If we study the beginnings of historical-comparative linguistics in the 19th century more fully, we'd have to recognize the importance of Schlegel's work and, of course, the contributions of Rasmus Rask and Jacob Grimm. An attempt to pin down a date for the first important breakthrough toward a new manner and method to study languages, their genetic origins and their development, would require considerable research into linguistics during the first half of the 19th century, and still one might not come up with a specific event. It is clear that later generations picked a convenient time and work and stuck by it without ever questioning its 
Se estudarmos o início da linguística histórico-comparativa no século XIX de modo mais amplo, teremos que reconhecer a importância do trabalho de Schlegel e, é claro, as contribuições de Rasmus Rask e Jacob Grimm. Uma tentativa de estabelecer uma data para o primeiro importante avanço em direção a uma nova maneira e a um novo método de estudar línguas, suas origens genéticas e seu desenvolvimento exigiria uma pesquisa considerável em linguística durante a primeira metade do século XIX, e, ainda assim, não se encontraria um evento específico. É evidente que gerações seguintes escolheram um momento e um trabalho convenientes e neles insistiram sem jamais questionar sua adequação. Podemos escolher a Gramática Comparativa de Bopp como o tipo de "exemplar" exigido pela morfologia das revoluções científicas de Thomas Kuhn, mas ela abrange apenas uma parte do que Grimm chamou de "a nova filologia".

Como se depreende desse trecho, o ano de 1808, quando foi publicada a obra de Schlegel, reuniria as condições para ser considerado o marco inicial de um avanço. Em todo caso, a data simbólica de 1816 é motivada pela publicação da influente obra de Bopp, que gozou ainda em vida do prestígio institucional e intelectual que seu trabalho the proporcionou. Admirador de Friedrich Schlegel e igualmente sanscritista, Bopp estava de acordo com a concepção de degenerescência a que a regularidade das línguas estava sujeita. Bopp também partilhava do pensamento de que a comparação entre línguas seria o meio para a reconstrução de formas não atestadas. Em suas investigações, a morfologia é o nível de articulação mais proeminente, enquanto a fonologia é secundária, e a sintaxe e a semântica praticamente não são abordadas. Em 1820, ele esclarece que o sânscrito é mais uma ao lado das demais línguas indo-europeias, ao argumentar que o sânscrito apresentava inovações que não haviam ocorrido, por exemplo, no grego. Ademais, expandiu o número de línguas pertencentes à família indo-europeia. Discussões de cunho metodológico são raras em sua obra, pois a metodologia emanaria do próprio trabalho, sem necessidade de demais explicações filosóficas (MORPURGO DAVIES, 2014c).

Em 1822, na segunda edição do primeiro volume de sua Deutsche Grammatik, Jacob Ludwig Karl Grimm (1785-1863) concluiu a descrição da primeira mutação sonora, ou consonântica (erste Lautverschiebung, a rigor, "primeiro deslocamento sonoro"), que havia sido previamente concebida por Rask, como dito anteriormente, desenvolvida pelo próprio Grimm e, posteriormente, ainda em seu tempo de vida, chamada de "Lei de Grimm". Diferentemente de Rask, entretanto, Grimm observou que as mudanças não ocorriam nas línguas trácias, senão na língua mãe, além de atentar para as recorrências cíclicas observadas em estágios mais tardios das línguas germânicas. Grimm assumia uma posição antinormativa, usava tipos de fontes variadas para a consecução de seu trabalho e lançava mão da combinação de uma abordagem empírica e histórica. Ademais,

appropriateness. We may choose Bopp's Comparative Grammar as the kind of 'exemplar' that Thomas Kuhn's morphology of scientific revolutions requires, but it covers only a part of what Grimm called 'die neue Philologie'.". 
diferentemente de Bopp, o foco de Grimm estava nos níveis de articulação fonético e morfofonêmico. Como no caso de seus contemporâneos, Grimm manifestava aspectos típicos do período romântico (valorização do folclore, adesão à ideia de superioridade de estágios anteriores da língua, assunção de reflexos de fatos sociais na língua, nacionalismo etc.). Sua obra é marcada pelo empirismo e historicismo (MORPURGO DAVIES, 2014c). Termos por ele criados, como stark e schwach ("forte" e "fraco"), umlaut e ablaut são utilizados até os dias atuais (ROBINS, 1967).

Por seu turno, Wilhelm von Humboldt (1737-1835) era um polímata envolvido em questões literárias, históricas, antropológicas, políticas e linguísticas. Ao contrário de Rask, Bopp e Jacob Grimm, considerados "tecnicistas", ocupou-se de questões filosóficas para justificar a autonomia da disciplina linguística e a faculdade da linguagem. Enquanto Morpurgo Davies (2014f, p. 98) o define como "an embarrassing thinker", Robins (1967, p. 174, tradução nossa7) afırma o seguinte sobre sua vida e obra:

Wilhelm von Humboldt foi um dos mais profundos pensadores sobre questões linguísticas gerais no século XIX, e é de se questionar se não Ihe teria sido concedida uma posição comparável à de Saussure como um dos fundadores do pensamento linguístico moderno, se seu estilo tivesse sido menos difuso, e suas ideias mais desenvolvidas e exemplificadas do que foram, e seus volumosos trabalhos fossem mais bem conhecidos e amplamente lidos. Ele foi um dos poucos linguistas do início do século XIX que não se concentraram predominantemente em história. De fato, ele não distinguia nitidamente os dois aspectos da linguística, sincronia e diacronia, e lançava mão de seu próprio conhecimento e do que leu em Bopp e outros para buscar respostas para suas questões de tipo linguístico essencialmente geral.

A linguística do início do século XIX é marcada por diversos eventos, como a redescoberta do sânscrito e a consolidação de uma linguística histórica e comparativa indo-europeísta, impulsionada notadamente por Bopp, e uma germânica, por Jacob Grimm. Some-se a esses Friedrich Christian Diez (1794-1876), que aplicou os mesmos métodos no âmbito da filologia românica. Finalmente, os desenvolvimentos dessas "novas filologias", que rivalizavam e se reconciliavam com a filologia clássica, tiveram impacto na formação

7 No original: "Wilhelm von Humboldt was one of the profoundest thinkers on general linguistic questions in the nineteenth century, and one wonders whether, if his style had been less diffuse and his ideas more worked out and exemplified than they were, and his voluminous works were better known and more widely read, he would not be accorded a position comparable to that given to de Saussure as one of the founders of modern linguistic thought. He was one of the few early nineteenth century linguists not concentrating predominantly on history. He did not, in fact, sharply distinguish the two aspects of linguistics, synchrony and diachrony, and he drew on his own knowledge and on what he read in Bopp and others to seek answers to the questions he raised of an essentially general linguistic kind". 
de professores, sobretudo no campo da recém-fundada Germanistik, com a recepção das ideias linguísticas de Jacob Grimm. Exceção feita a Sir William Jones, um homem do século XVIII considerado precursor da linguística, Rask, Bopp, Grimm e Humboldt vivenciaram o contexto do século XIX, fato que implica sua participação no processo de institucionalização da disciplina linguística e que, por conseguinte, pode ser considerado, entre outros, um dos fatores marcantes que distinguem o século XIX dos séculos XVII e XVIII. À época desses precursores e/ou fundadores da linguística, observou-se a expansão das universidades e periódicos linguísticos, sobretudo na Alemanha. Além das mudanças sociais e políticas, o surgimento dessa nova Philologie se deu em um ambiente de consolidação e mudanças profundas nas universidades, como a dissolução da hierarquia das faculdades, ênfase em pesquisa, especialização e autonomização das disciplinas, e os termos-chave então em voga eram filologização, reivindicação por cientificidade, profissionalização e especialização (MEVES, 2001).

Não se pretende aqui catalogar uma série de obras e autores que empreenderam tentativas de classificação das línguas germânicas nos contextos descritos, tampouco é possível fazer uma análise aprofundada do tratamento dado à questão. Contudo, alguns exemplos são suficientes para ilustrar como o tema foi tratado desde então. É importante observar que, como o início do século XIX coincidia com o início de uma nova filologia, aquele também era, ainda, o começo de uma tradição que, ao contrário do que ocorria outrora, teria continuidade e não mais seria objeto de iniciativas isoladas e descontinuadas da parte de alguns poucos eruditos. É natural, portanto, que aqueles que estavam envolvidos na fundação da nova disciplina também fossem os responsáveis pelas primeiras investigações sobre as origens das línguas germânicas. Dentre os fundadores, por exemplo, Grimm propõe, no primeiro volume de sua Deutsche Grammatik (1819, L-LI), uma divisão de tribos germânicas em quatro grandes grupos: (i) os godos (Gothen) e as tribos que Ihes eram mais próximas, a saber, os gépidas (Gepiden), os hérulos (Heruler) e os vândalos (Vandalen); (ii) os lombardos (Langobarden), os "bávaros" (Baiern), os burgúndios (Burgunden), os alamanos (Alemannen) e os francos (Franken); (iii) os saxões (Sachsen), os "vestfalianos" (Westphalen), os "frísios" (Friesen) e os anglos (Angeln); e (iv) os "nórdicos" (Nordischen). Antes mesmo de Grimm, Rasmus Rask, um dos precursores da linguística histórico-comparativa, também se ocupara de classificar as línguas.

\section{Os consolidadores}

Alguns dos fundadores das ciências da linguagem, como Bopp, August Pott (1802-1887), Rask e Jacob Grimm, debruçaram-se sobre a questão da reconstrução de proto-formas indo-europeias, ainda que de forma mais ou menos sistemática. Esse cenário foi alterado por August Schleicher (1821-1868), que, em seu Compendium der vergleichenden Grammatik der Indogermanischen Sprachen ("Compêndio da gramática das línguas indo-europeias", 1861), realçou a importância da reconstrução fonológica do indo-europeu, consolidou a teoria da árvore genealógica (Stammbaumtheorie) e insistiu no estabelecimento de 
leis fonéticas regulares. Antes de Schleicher, ninguém havia se ocupado de reconstruir proto-formas, como sugerira Friedrich Schlegel (KOERNER, 1999a). Tal era a confiança de Schleicher em suas reconstruções que, em 1868, ele reconstruiu uma fábula completa em proto-indo-europeu. Sua atitude frente à reconstrução de um ancestral proto-indoeuropeu terminou por consolidar a precedência dessa língua em relação ao sânscrito, antes já aludida por Bopp (1974 [1820], p. 15, tradução nossa):

\begin{abstract}
Não creio que o grego, o latim e outras línguas europeias devam ser considerados derivados do sânscrito no estado em que o encontramos nos livros indianos; sinto-me mais inclinado a considerá-los variações subsequentes de uma língua original, que, no entanto, o sânscrito preservou mais perfeitamente que os dialetos da mesma família. Mas, embora, portanto, a língua dos Brâmanes nos permita mais frequentemente conjecturar a forma primitiva do grego e do latim do que o que descobrimos nos autores e monumentos mais antigos, [o grego e o latim], por seu turno, podem, não raramente, elucidar a gramática sânscrita. Isto é, embora o sânscrito tenha preservado muitas formas gramaticais, as quais supostamente teriam existido em grego, latim, gótico etc., há casos em que ocorre o inverso, em que formas gramaticais, perdidas no sânscrito, foram preservadas no grego ou no latim.
\end{abstract}

A exemplo da reconstrução de proto-formas, a árvore genealógica tampouco foi uma novidade introduzida por Schleicher, mas ficou a ele associada em razão de sua ênfase na reconstrução, que permitiu seu desenvolvimento por linguistas que o sucederam. A proposição da árvore com ramificações representantes da 'língua mãe' e suas descendentes marcou o estabelecimento de relações genéticas, a indicação do grau de parentesco entre as línguas, a concepção dos procedimentos para a reconstrução em relação a estágios intermediários, a representação gráfica da cronologia do desenvolvimento das línguas descendentes e subagrupamentos de línguas a serem reconstruídas. Por fım, a despeito das correspondências regulares e leis fonéticas descobertas por gerações anteriores, Schleicher, juntamente com Georg Curtius (18201885), notabilizou-se pela coerência no desenvolvimento dessas leis e pela consciência metodológica que demonstrava (MORPURGO DAVIES, 2014d).

8 No original: "I do not believe that the Greek, Latin, and other European languages are to be considered as derived from the Sanskrit in the state in which we find it in Indian books; I feel rather inclined to consider them altogether as subsequent variations of one original tongue, which, however, the Sanskrit has preserved more perfect than its kindred dialects. But whilst therefore the language of the Brahmans more frequently enables us to conjecture the primitive form of the Greek and Latin languages than what we discover in the oldest authors and monuments, the latter on their side also may not unfrequently elucidate the Sanskrit grammar. That is to say, whilst the Sanskrit has preserved many grammatical forms, which can be supposed to have formerly existed in Greek, Latin, Gothic, \&c. there are instances where the reverse is the case, where grammatical forms, lost in the Sanskrit, have been preserved in Greek or Latin". 
Cabe ressaltar que Schleicher havia estudado botânica durante sua juventude. Já em 1850, ele defendia a ideia de que a linguística pertencia às Naturwissenschaften ("ciências naturais"), não às Geisteswissenschaften (grosso modo, "humanidades"). Tamanho era seu apreço pelas ciências naturais que isso causou equívocos na historiografia da linguística, a qual atribuiu a influência direta de Charles Darwin (1809-1882) sobre suas ideias, como discutido por Koerner (1989a). No tempo de Schleicher, suas ideias foram dominantes e perduraram até pouco antes de sua morte, quando novas descobertas foram feitas, tornando seu modelo original obsoleto. Sua clássica teoria da árvore genealógica, por exemplo, sofreu críticas por não acondicionar ocorrências como contato, convergência entre línguas e graus de difusão de inovações linguísticas, como nos casos de variação dialetal. Por essa razão, oferece uma interpretação verticalizada das relações genéticas entre as línguas. Uma alternativa à Stammbaumtheorie foi apresentada por Johannes Schmidt (1843-1901), cujo modelo denominado Wellentheorie ("teoria das ondas") representava de maneira horizontal a difusão de certos processos ao longo de um contínuo linguístico, porém, ambos os modelos foram, ainda no século XIX, considerados mutuamente complementares. Ainda como pertencentes a esse período, podemos listar August Fick (1833-1916), que também produziu reconstruções, e Georg Curtius, que foi professor da maior parte dos neogramáticos (MORPURGO DAVIES, 2014e).

Quanto ao agrupamento das línguas germânicas, desse período podemos destacar Schleicher (1860), que propõe ter havido uma divisão tripartite das línguas germânicas após a desintegração de uma "língua germânica original" (Deutsche Grundsprache), da seguinte maneira: o gótico (Gotisch), um (aproximadamente) "germânico ocidental" (Deutsch) e um "nórdico" (Nordisch).

\section{Os desenvolvedores: notadamente, os neogramáticos}

Os neogramáticos (Junggrammatiker, a rigor, "jovens gramáticos") se compunham, originalmente, pelos indo-europeístas Karl Friedrich Christian Brugmann (1849-1919), Johann Heinrich August Leskien (1840-1916), Hermann Osthoff (1847-1909) e Berthold Gustav Gottlieb Delbrück (1842-1922) e pelos germanistas Hermann Otto Theodor Paul (1846-1921) e Eduard Georg Sievers (1850-1932). O indo-europeísta dinamarquês Karl Adolf Verner (1846-1896) tinha um vínculo mais distante com os neogramáticos, embora fizesse parte do grupo de Leipzig (MORPURGO DAVIES, 2014e). Theodor Wilhelm Braune (1850-1926) e Friedrich Kluge (1856-1926) faziam parte da geração de estudantes e, portanto, não participaram do processo de emergência dos neogramáticos, devendo, preferivelmente, ser considerados expoentes do seu programa já devidamente consolidado (EINHAUSER, 2001). O ano de 1876 é denominado por Hoenigswald (1978) "annus mirabilis", em razão de uma série de publicações dos integrantes do núcleo neogramático no mesmo ano. Uma peculiaridade dos neogramáticos em relação aos seus predecessores era sua premissa de que mudanças fonéticas não apresentavam exceções, a menos se por efeito de analogia, força que modela outras formas: 
[...] uma aparente exceção à lei de Grimm se mostra não como uma exceção, mas simplesmente como o resultado da aplicação de uma outra e até então insuspeitada lei. A partir disso, o princípio mais geral é facilmente deduzido: não há exceções; exceções aparentes apenas indicam que a respectiva lei ainda não foi descoberta. (FOX, 1995, p. 31, tradução nossa9).

A trajetória dos neogramáticos foi repleta de controvérsias. Uma delas remonta aos ataques agressivos contra seus predecessores, como, por exemplo, no caso de alusão pejorativa ao trabalho de Schleicher, ao qual se referiam como "pesquisa linguística arcaica" ("ältere Sprachforschung"), como observa Jankowsky (2001a). Contudo, uma suposta ruptura, que caracterizaria a descontinuidade em relação ao que se praticava até então, seria sobretudo retórica. A esse respeito, Koerner (1989c, p. 95, tradução nossa ${ }^{10}$ ) faz a seguinte afirmação:

[...] seu trabalho foi realizado na 'matriz disciplinar' estabelecida em grande medida por Schleicher, e o que para muitos da época e também para gerações posteriores de linguistas parecia um "avanço", era pouco mais que uma articulação adicional, uma extensão do "paradigma schleicheriano".

Amsterdamska (1987, p. 101, tradução nossa ${ }^{11}$ ) parece concordar com a concepção de que o programa supostamente inovador dos neogramáticos fosse questionável, mas pondera:

Se a proclamação de inovações metodológicas por parte dos neogramáticos era mais retórica do que descritiva de sua prática real, no entanto, sua compreensão da natureza da língua e de sua história, sua concepção da linguística como uma ciência e suas justificativas para a prática de pesquisa adotada eram novas.

9 No original: "[...] an apparent exception to Grimm's Law is shown to be not an exception at all, but simply the result of the application of another, and hitherto unsuspected, law. From this the more general principle is easily deduced: there are no exceptions; apparent exceptions merely indicate that the relevant law has not yet been found".

10 No original: "[...] their work was carried on within the 'disciplinary matrix' established largely by Schleicher, and what appeared to many at the time, and to later generations of linguists as well, as a 'breakthrough' was little more than a further articulation, an extension of the 'Schleicherian Paradigm'.".

11 No original: "If the Neogrammarians' proclamation of methodological innovations were more rhetorical than descriptive of their actual practice, nevertheless their understanding of the nature of language and of its history, their conception of linguistics as a science, and their justifications of the adopted research practice were new.". 
A despeito das disputas exageradas travadas pelos neogramáticos com seus "oponentes", eles obtiveram notoriedade sem precedentes em razão de sua vasta e profícua produtividade, de maneira que, entre 1880 e 1890, tornaram-se incontestes na Europa, ainda que houvesse vozes dissidentes entre seus contemporâneos, como Hugo Ernst Mario Schuchardt (1842-1927), por exemplo (MURRAY, 2006). Um de seus êxitos mais significativos foi a solução da questão referente a uma série de exceções à Lei de Grimm. O autor dessa solução para a até então inexplicável variação aparentemente arbitrária entre oclusivas surdas e sonoras no germânico em ambiente fonológico idêntico foi Karl Verner (1877), quem observou que tal alternância tinha estrita relação com a posição do acento no indo-europeu. Essa descoberta reforçou a hipótese da regularidade da mudança sustentada pelos neogramáticos, segundo os quais havia uma suposta infalibilidade das leis fonéticas (Ausnahmslosigkeit der Lautgesetze).

Segundo Jankowsky, a despeito do programa positivo que os neogramáticos propunham, sua retórica, sobretudo no que diz respeito aos seus contemporâneos sêniores, era agressiva e desmesurada, ainda que difusa e, muitas vezes, pouco elaborada, o que pode ter retardado a difusão de suas ideias. Sua atitude arrogante pode ser ilustrada por sua reivindicação por ineditismo, sem a demonstração do devido reconhecimento aos feitos de seus predecessores. Duas características importantes dos neogramáticos são a assunção de fatores psicológicos como igualmente preponderantes na mudança linguística, em contraposição a uma abordagem meramente mecanicista ou fisiológica, e a preterição da língua escrita em favor da falada para uma melhor compreensão do fenômeno da mudança (JANKOWSKY, 2001b).

Uma investigação não exaustiva sobre a origem das línguas germânicas pode pressupor, por exemplo, a escolha de um ou outro exemplar de cada período estudado. Como vimos anteriormente, há uma controvérsia sobre se os neogramáticos teriam estabelecido um novo paradigma ou se estariam apenas dando continuidade ao paradigma schleicheriano. Uma obra de Schleicher, como Die Deutsche Sprache ${ }^{12}$ (1860), pode ser comparada com uma de viés neogramático com o propósito de se investigar se houve, de fato, inovação por parte dos neogramáticos, ao menos no que diz respeito a esse tema, especificamente. A Urgermanische Grammatik ("Gramática do proto-germânico", 1896) de Streitberg, por exemplo, oferece-nos uma abordagem neogramática em que se apresenta uma tripartição das línguas germânicas em um "germânico oriental" (Ostgermanisch), um "germânico setentrional" (Nordgermanisch) e um "germânico ocidental" (Westgermanisch). Embora faça uso de taxonomia distinta da de Schleicher, a manutenção de uma classificação tripartite das línguas germânicas por parte de Streitberg sugere antes uma continuidade do que uma ruptura, sobretudo se considerarmos que antes de Schleicher

12 Diferentemente do sentido de 'germânico' sugerido por Jacob Grimm com o emprego de 'Deutsch' em sua Deutsche Grammatik, o mesmo termo significa 'germânico ocidental', na obra de Schleicher, que se contrapõe a um Nordisch ('nórdico') e ao Gotisch ('gótico'), sendo este último o único representante do ramo oriental das línguas germânicas. 
e depois dos neogramáticos houve propostas que não pressupunham necessariamente uma tripartição das línguas germânicas. Em todo caso, a hipótese sobre uma eventual inovação, neste caso específico, precisaria ser desenvolvida alhures. O simples fato de haver uma controvérsia sobre se os neogramáticos haveriam ou não rompido com seus antecessores e estabelecido um novo paradigma justificaria a comparação e análise dessas obras e de seus autores antes de se esboçar qualquer conclusão a esse respeito.

\title{
Os estruturalistas
}

Por fim, um quarto e último momento que aqui delimitamos é o ano da publicação póstuma do Cours de linguistique générale (1916), de autoria do suiço Ferdinand Mongin de Saussure (1857-1913). A respeito do Cours, Koerner (1999a, p. 91, tradução nossa ${ }^{13}$ ) faz a seguinte afırmação:

\begin{abstract}
Parece que pouco precisa ser dito sobre a importância das aulas de Saussure sobre linguística geral neste século [...]. Se adotássemos a morfologia das revoluções científicas de Kuhn, encontraríamos no Cours de linguistique générale o "exemplar" par excellence para o pensamento linguístico do século XX e, pode-se acrescentar, para grande parte da prática linguística, sem mencionar o impacto que o ensinamento de Saussure teve em outros campos, como a psicologia, a antropologia e a teoria literária [...]. De fato, no caso do Cours, chegamos o mais próximo possível de identificar um trabalho que tenha mudado profundamente o curso da linguística. Os Aspects of the Theory of Syntax de Chomsky, de 1965, poderiam reivindicar um status comparável apenas [no que] diz respeito ao estudo da sintaxe, e não à linguística em termos gerais.
\end{abstract}

Essa data é considerada como um marco inicial do que veio a ser chamado, no final dos anos 1920, de estruturalismo, que correspondia às abordagens de um grupo de linguistas que partilhavam de certos princípios e divergiam sobre outros específicos. 0 estruturalismo se desenvolveu sobremaneira na Europa e nos Estados Unidos da América, porém, não necessariamente de maneira uniforme (JOSEPH, 1995). Após a publicação do Cours, a linguística histórica tradicional continuou a ser desenvolvida na Europa, em particular na Alemanha, até meados do século XX, enquanto, nos Estados Unidos, seu

13 No original: "It appears that little needs to be said about the significance of Saussure's lectures on general linguistics in this century [...]. If we were to adopt Kuhn's morphology of scientific revolutions we would find in the Cours de linguistique générale the 'exemplar' par excellence for 20th-century linguistic thought and, one may add, for much of linguistic practice, not mention the impact Saussure's teaching has had on other fields such as psychology, anthropology, and literary theory [...]. Indeed, in the case of the Cours we have come as close as we ever will to identifying a work that has profoundly changed the course of linguistics. Chomsky's 1965 Aspects of the Theory of Syntax could only lay claim to a comparable status [where] the study of syntax, not linguistics in general terms, is concerned". 
declínio era evidente já nos anos 1940. A crítica de Saussure aos seus contemporâneos se devia, sobretudo, à indefinição sobre os objetivos da linguística. Entre as dicotomias por ele propostas para a organização do campo científico, encontramos a distinção entre diacronia e sincronia. A linguística até então praticada era essencialmente histórica, de modo que, ao fazer tal distinção, Saussure sugeria um equilíbrio entre ambas. Entretanto, o efeito prático dessa distinção foi a maior ênfase dada aos estudos sincrônicos, de modo que a linguística histórica terminou por ser, de certa forma, marginalizada. Apesar de o viés estruturalista haver se tornado praticamente sinônimo de linguística descritiva sincrônica, a teoria da mudança linguística se beneficiou de contribuições feitas naquele período, como a catalogação de mudanças como fonologização, desfonologização e refonologização, realizada pela Escola de Praga, a criação de termos linguísticos, como fusão e fissão (primária e secundária), pelos estruturalistas estadunidenses, etc. (MURRAY, 2006).

Anteriormente, mencionamos o "Modelo de Descontinuidade-vs.-Continuidade", de Koerner (1989b). Um exemplo eloquente de sua capacidade explanatória é oferecido pela afirmação de Kufner (1972a, p. IX-XI, tradução nossa ${ }^{14}$ ), que contempla tanto o período neogramático como o estruturalista:

Germanistas nos Estados Unidos há tempos estão cientes das deficiências do único manual germânico escrito em inglês que poderíamos recomendar aos nossos alunos: a Comparative Germanic Grammar (1939), de Eduard Prokosch. Mesmo quando foi publicado, esse trabalho já estava, em alguns aspectos, desatualizado. Era essencialmente um produto - e um dos melhores - da abordagem neogramática da linguagem que havia sido desenvolvido no final do século XIX []] enquanto, na década de 1930, os linguistas mais ativos nos Estados Unidos estavam trabalhando entusiasticamente uma nova abordagem, que logo ficou conhecida como "estruturalismo". [...] Talvez, quando nosso presente volume for publicado, ele também esteja parcialmente desatualizado: ele oferecerá, de modo geral, uma abordagem estrutural do proto-germânico, numa época em que a gramática gerativo-transformacional estará chegando para dominar o campo.

14 No original: "Germanists in the United States have long been aware of the shortcomings of the only Germanic handbook written in English which we could recommend to our students: Eduard Prokosch's Comparative Germanic Grammar (1939). Even when it was published, this work was in some respects already out of date. It was essentially a product-and one of the finest-of the neogrammarian approach to language that had been developed toward the end of the 19th century[], whereas by the 1930's the most active linguists in the United States were enthusiastically working out a new approach that soon came to be known as 'structuralism.' [...] Perhaps, by the time our present volume is published, it will also be partly out of date: it will offer by and large a structural approach to Proto-Germanic at a time when transformational-generative grammar is coming to dominate the field. For this we do not apologize. Any writer who tries to summarize a generation of scholarship must inevitably appear as a kind of epigone". 
Não nos desculpamos por isso. Qualquer escritor que tente resumir uma geração do conhecimento deve se parecer inevitavelmente com uma espécie de epígono.

Como se pode notar, não houve um abandono do programa neogramático e da linguística histórica de maneira geral, apesar de o primeiro quartel do século XX ter testemunhado a emergência e a ascensão do estruturalismo, que se concentrou na linguística sincrônica. A publicação de obras de cunho neogramático não cessou após a publicação do Cours de Saussure. Nos países europeus de língua alemã e na Itália, o "paradigma saussuriano" não se firmaria até os anos 1960 (KOERNER, 1989b). Igualmente, o período estruturalista não se estendeu somente até o ano de 1968, quando "[...] uma revolta contra o estruturalismo se tornou parte dos levantes estudantis [...]" (JOSEPH, 1995, p. 227, tradução nossa ${ }^{15}$ ), e o gerativismo se tornou, então, saliente, primeiramente nos Estados Unidos.

O período estruturalista guardava semelhanças e diferenças em relação ao neogramático. Uma semelhança importante reside no fato de que a hipótese da regularidade da mudança foi mantida no programa estruturalista. Por outro lado, um aspecto da abordagem saussuriana, que se opunha ao que assumiam os neogramáticos, mas passou a ser amplamente aceito, é a primazia da sincronia no sentido de que o tratamento diacrônico da língua pressupõe sua descrição sincrônica. Ademais, a ênfase no tratamento da língua como um sistema trouxe efeitos benéficos para o entendimento dos mecanismos envolvidos na mudança linguística, vista como a mudança de um sistema para outro cronologicamente posterior (MURRAY, 2006).

No que tange aos estudos sobre o agrupamento das línguas germânicas nesse período, um exemplo de abordagem estruturalista é oferecido por Kufner (1972b). Após examinar os trabalhos de outros autores, sobretudo de seus contemporâneos, que defendem a ideia tradicional de divisão tripartite, de alguns que assumem diferentes divisões bipartites e de outros que pensam que o conhecimento e os métodos disponíveis não lhes permitem solucionar os problemas relativos à divisão das línguas germânicas, Kufner adere a este último grupo, argumentando que talvez jamais os estudiosos cheguem a um consenso sobre o seu estado original (KUFNER, 1972b).

\section{A geografia linguística}

Nesse amplo contexto de mudanças mais ou menos profundas, os estudos sobre as origens das línguas germânicas tiveram como foco o agrupamento dos dialetos antigos em seu período histórico, ou seja, literário, com base em runas e/ou textos mais ou menos extensos. Uma periodização como a que abordamos contempla, ao menos parcialmente, as tradições de pesquisa que tiveram esse problema como objeto de investigação, inclusive durante o período pré-científico anterior ao século XIX. Contudo,

15 No original: "a revolt against structuralism became part of the student uprisings". 
tal periodização é concebida de modo a contemplar questões "maiores", que abarcam eventos socioculturais importantes, como a institucionalização e a autonomização da disciplina linguística, e eventos intradisciplinares, como mudanças de visão sobre a língua, de enfoques teóricos, metodológicos etc.

Seria uma trivialidade afirmar que a origem das línguas tenha sido um tema caro aos estudiosos do século XIX, quando as investigações sobre as línguas tinham um viés predominantemente histórico e comparativo. Desse modo, a maior parte dos estudiosos das línguas germânicas está devidamente contemplada por essa periodização, já que esteve representada no âmbito de todas as tradições de pesquisa abarcadas por aqueles períodos. Neles, houve inúmeros autores que abordaram a questão das origens e do desenvolvimento histórico das línguas germânicas, seja como foco central ou como um tema secundário de seus trabalhos.

Ao discutir as origens da sociolinguística moderna, Koerner (1995) apresenta-as a partir de uma genealogia muito elucidativa, embora assumidamente simplista, em que traça uma trajetória que tem como ponto de partida William Dwight Whitney (1827-1894), passa por William Labov (nasc. 1927) e se estende aos seus sucessores. O argumento central de Koerner é o de que a sociolinguística moderna teve suas origens na geografia dialetal. Labov foi discípulo de Uriel Weinreich (1926-1967), filho de Max Weinreich (1894-1969), que havia se doutorado em língua e literatura iídiche sob a supervisão de Victor Karl Paul Ferdinand Wrede (1863-1934). Este, por seu turno, foi sucessor de Georg Wenker (1852-1911) na Universidade de Marburgo. Wenker foi um dos pioneiros nos estudos dialetológicos, fundador da Escola de Marburgo (Marburger Schule) e do Atlas Linguístico do Alemão (Deutscher Sprachatlas-DSA), projeto ao qual Wrede deu continuidade.

Como se pode notar, a tradição que Koerner chama de geografia dialetal teve grande importância no desenvolvimento da sociolinguística moderna. Ao longo de sua história, essa tradição recebeu também outras designações, como geografia linguística, geolinguística e linguística areal (HILDEBRANDT, 1998) ou, simplesmente, dialetologia. Contudo, essa tradição não foi importante apenas para a sociolinguística e tampouco tem suas raízes no final do século XIX. Suas origens remontam a Johann Andreas Schmeller (1785-1852), contemporâneo de Grimm. De acordo com Putschke (2001), Schmeller pode ser considerado fundador da pesquisa dialetal científica, tendo publicado em 1821 sua obra sobre os falares bávaros, de maneira que o surgimento da dialetologia não pode ser atribuído a uma reação aos neogramáticos. A linguística histórica e a dialetologia se desenvolvem de maneira independente, porém, essa situação seria alterada na segunda metade do século XIX. Ainda que tivesse seus próprios objetivos e métodos, a dialetologia passa a servir também como uma disciplina complementar à linguística histórica, depois de os neogramáticos mudarem seu objeto de investigação, notadamente das fontes escritas mais antigas para as línguas e dialetos modernos e, assim, o foco deixa de ser a reconstrução da proto-língua. Essa avaliação positiva dos 
dialetos aumenta, então, a importância da dialetologia, que passa a fornecer dados para a linguística histórica por meio de seus dicionários e de suas gramáticas. A dialetologia também contribuiria com suas inovações metodológicas, como o desenvolvimento da cartografia linguística, o que terminou por confrontar a visão histórica dos neogramáticos com uma visão do espaço geográfico. Contudo, como ressalta Putschke, o paradigma histórico era ainda tão dominante que as cartas linguísticas sincrônicas produzidas pela dialetologia logo receberam uma interpretação histórica, tornando-se um complemento também metodológico da linguística histórica.

Estudiosos como Ferdinand Wrede, Theodor Frings (1886-1968), Ernst Schwarz (18951983) e Viktor Maksimovich Schirmunski [também Zhirmunskiy] (1891-1971), todos envolvidos em trabalhos dialetológicos, tiveram bastante visibilidade na discussão sobre o agrupamento das línguas germânicas ao longo de grande parte do século XX, passando a ser recorrentemente citados por estudiosos de outras tradições em discussões sobre esse problema. Um exemplo de ataque mais vigoroso a ideias de um dialetólogo é a resenha de 1952 de autoria de Hans Kuhn (1899-1988) sobre o livro intitulado Goten, Nordgermanen, Angelsachsen (1951), de Schwarz, reconhecido líder intelectual e organizacional (STEGER, 1984). Ainda que não tenha se tornado a "tradição central" de sua disciplina, a dialetologia representa uma longa e continuada tradição de pesquisa que, particularmente com referência aos estudos sobre o agrupamento das línguas germânicas, ocupou um espaço de centralidade na discussão, reavivando um debate que havia minguado e se acomodado nas bases já estabelecidas por outras tradições envolvidas com a linguística histórica.

\section{Considerações finais}

A história das ciências da linguagem a partir do início do século XIX é marcada por diversos eventos socioculturais e intelectuais que o distinguem do período pré-científico dos séculos anteriores. A historiografia canônica distingue, na Europa do século XIX, ao menos três gerações de estudiosos, majoritariamente alemães, enquanto no século $X X$ se desenvolveram diferentes estruturalismos, nos Estados Unidos e na Europa, com diferentes ritmos de disseminação de ideias no espaço e no tempo, caracterizando continuidades e descontinuidades de tradições. Assim, a dinâmica da história da disciplina pode ser vista como uma alternância de linhas de atividade principais e correntes secundárias (KOERNER, 1989b).

Em todos os períodos em questão, os estudos sobre as origens das línguas germânicas se concentraram sobretudo em tentativas de agrupamento dos dialetos antigos, com o propósito específico de estabelecer subfamílias linguísticas, ainda que não necessariamente homogêneas, para, então, rastrear seu desenvolvimento histórico até um estágio anterior comum, tal como se tencionou no âmbito dos estudos indoeuropeístas, em relação ao proto-indo-europeu. A dialetologia não chegou a se tornar a 
tradição central (ou cinosura) da linguística, tendo permanecido como "tradição periférica" (HYMES, 1974) e coexistido com as demais tradições desde a primeira metade do século XIX, estreitando suas relações com a linguística histórica no período neogramático, a partir de 1878. Apesar disso, uma breve análise da história dos estudos sobre a questão das origens das línguas germânicas revela que as contribuições de dialetólogos foram alvo de bastante atenção e reação ao longo de parte do século XX. Para não banalizar o termo na forma original concebida por Hymes, pode-se arriscar dizer que, ao menos no que diz respeito a esse problema, especificamente, os estudos dialetológicos ocuparam uma posição de centralidade de uma subdisciplina preocupada com as origens das línguas germânicas, uma questão que surgiu há séculos e vem sendo tratada cientificamente desde o início do século XIX, no âmbito de diferentes tradições de pesquisa.

\section{REFERÊNCIAS}

ADELUNG, J. C. Mithridates oder allgemeine Sprachenkunde. Zweyter Theil. Berlin: Vossische Buchhandlung, 1809.

AMSTERDAMSKA, O. Schools of thought: the development of linguistics from Bopp to Saussure. Dordrecht: D. Reidel Publishing Company, 1987.

BOPP, F. Analytical Comparison of the Sanskrit, Greek, Latin, and Teutonic Languages, shewing the original identity of their grammatical structure. 1820. Reimpressão. Amsterdam: Benjamins, 1974.

BOPP, F. Über das Conjugationssystem der Sanskritsprache in Vergleichung mit jenem der griechischen, lateinischen, persischen und germanischen Sprache. Frankfurt am Main: Andräische Buchhandlung, 1816.

EINHAUSER, E. Die Entstehung und frühe Entwicklung des junggrammatischen Forschungsprogramms. In: AUROUX, S. et ali. History of the language sciences: an international handbook on the evolution of the study of language from the beginnings to the present. v. 2. Berlin/New York: Walter de Gruyter, 2001a. p. 1338-1350.

FOX, A. Background to the Comparative Method. In: FOX, A. Linguistic reconstruction: an introduction to theory and method. Oxford New York: Oxford University Press, 1995. p. 17-36.

FULDA, F. C. Sammlung und Abstammung germanischer Wurzel-Wörter, nach der Reihe menschlicher Begriffe. Georg Olms Verlag, 1776. 
GRIMM, J. Deutsche Grammatik. Erster Theil. Göttingen: Dietriche Buchhandlung, 1819 (1. ed.), 1822 (2. ed.) e 1840 (3. ed.).

HILDEBRANDT, R. Der Beitrag der Sprachgeographie zur Sprachgeschichtsforschung. In: BESCH, W. Sprachgeschichte: ein Handbuch zur Geschichte der deutschen Sprache und ihrer Erforschung. 2. ed. Berlin; New York: de Gruyter, 1998. p. 495-519.

HOENIGSWALD, H. M. The annus mirabilis 1876 and posterity. Transactions of the Philological Society, v. 76, n. 1, p. 17-35, 1978.

HYMES, D. Introduction: Traditions and paradigms. Studies in the History of Linguistics, p. 1-38, 1974.

JANKOWSKY, K. R. The crisis of historical-comparative linguistics in the 1860s. In: AUROUX, S. et ali. History of the language sciences: an international handbook on the evolution of the study of language from the beginnings to the present. v. 2. Berlin/New York: Walter de Gruyter, 2001a. p. 1326-1338.

JANKOWSKY, K. R. The consolidation of the neogrammarian framework. In: AUROUX, S. et ali. History of the language sciences: an international handbook on the evolution of the study of language from the beginnings to the present. v. 2. Berlin/New York: Walter de Gruyter, 2001b. p. 1350-1367.

JONES, S. W. The Third Anniversary Discourse, on the Hindus, delivered 2d of February, 1786. In: TEIGNMOUTH, L. (ed.). The Works of Sir William Jones: With the Life of the Author by Lord Teignmouth. v. 3. Cambridge: Cambridge University Press. 1807. p. 24-46.

JOSEPH, J. E. Trends in twentieth-century linguistics: an overview. In: KOERNER, E. F. K.; ASHER, R. E. Concise history of the language sciences: from the Sumerians to the cognitivists. New York: Pergamon, 1995. p. 221-233.

KOERNER, E. F. K. The Concept of 'Revolution' in Linguistics: Historical, methodological, and philosophical issues. In: KOERNER, E. F. K. Linguistic historiography: projects \& prospects. Amsterdam, Philadelphia: J. Benjamins, 1999a. p. 85-96.

KOERNER, E. F. K. The Idea of Reconstruction in Comparative Linguistics: History and some modem debates. In: KOERNER, E. F. K. Linguistic historiography: projects \& prospects. Amsterdam Philadelphia: J. Benjamins, 1999b. p. 97-116. 
KOERNER, E. F. K. Toward a History of Modern Sociolinguistics. Professing linguistic historiography. Amsterdam/Philadelphia: John Benjamins Publishing Company, 1995. p. 117-134.

KOERNER, E. F. K. On the Problem of 'Influence' in Linguistic Historiography. In: KOERNER, E. F. K. Practicing linguistic historiography: selected essays. Amsterdam Philadelphia: J. Benjamins Pub. Co, 1989a. p. 31-46.

KOERNER, E. F. K. Models in Linguistic Historiography. In: KOERNER, E. F. K. Practicing linguistic historiography: selected essays. Amsterdam Philadelphia: J. Benjamins Pub. Co, 1989b. p. 47-59.

KOERNER, E. F. K. The Neogrammarian Doctrine: Breakthrough or extension of the Schleicherian paradigm. A problem in linguistic historiography. In: KOERNER, E. F. K. Practicing linguistic historiography: selected essays. Amsterdam Philadelphia:

J. Benjamins Pub. Co, 1989c. p. 79-100.

KUFNER, H. L. Foreword. In: COETSEM, F. van; KUFNER, H. L. Toward a grammar of ProtoGermanic. Tübingen: M. Niemeyer, 1972a. p. ix-xi.

KUFNER, H. L. The Grouping and Separation of the Germanic Languages. In: COETSEM, F. van; KUFNER, H. L. Toward a grammar of Proto-Germanic. Tübingen: M. Niemeyer, 1972b. p. 71-98.

KUHN, H. Besprechung von: E. Schwarz, Goten, Nordgermanen, Angelsachsen. Zeitschrift für Deutsches Altertum und Deutsche Literatur, v. 84, n. 2, p. 45-52, 1952.

KUHN, T. S. The Structure of Scientific Revolutions. 2. ed. Chicago: University of Chicago Press, 1970.

MEVES, U. Die Entstehung und frühe Entwicklung der Germanischen Philologie. In: AUROUX, S. et ali. History of the language sciences: an international handbook on the evolution of the study of language from the beginnings to the present. v. 2. Berlin/New York: Walter de Gruyter, 2001. p. 1286-1294.

MORPURGO DAVIES, A. Historiography and Institutions. In: MORPURGO DAVIES, A. Nineteenth-century linguistics. New York: Routledge, Taylor \& Francis Group, 2014a. p. 1-23. 
MORPURGO DAVIES, A. Friedrich Schlegel and the discovery of Sanskrit. In: MORPURGO DAVIES, A. Nineteenth-century linguistics. New York: Routledge, Taylor \& Francis Group, 2014b. p. 59-82.

MORPURGO DAVIES, A. Comparative and historical grammar: Rask, Bopp and Grimm. In: MORPURGO DAVIES, A. Nineteenth-century linguistics. New York: Routledge, Taylor \& Francis Group, 2014c. p. 124-150.

MORPURGO DAVIES, A. Comparative studies and the diffusion of linguistics. In: MORPURGO DAVIES, A. Nineteenth-century linguistics. New York: Routledge, Taylor \& Francis Group, 2014d. p. 151-189.

MORPURGO DAVIES, A. The neogrammarians and the new beginnings. In: MORPURGO DAVIES, A. Nineteenth-century linguistics. New York: Routledge, Taylor \& Francis Group, 2014e. p. 226-278.

MORPURGO DAVIES, A. Wilhelm von Humboldt, general linguistics and linguistic typology. In: MORPURGO DAVIES, A. Nineteenth-century linguistics. New York: Routledge, Taylor \& Francis Group, 2014f. p. 98-123.

MORPURGO DAVIES, A. The old and the new: data collection and data comparison. In: MORPURGO DAVIES, A. Nineteenth-century linguistics. New York: Routledge, Taylor \& Francis Group, 2014g. p. 24-58.

MURRAY, R. W. The place of historical linguistics in the age of structuralism. In: AUROUX, S. et ali. History of the language sciences: an international handbook on the evolution of the study of language from the beginnings to the present. v. 3. Berlin/New York: Walter de Gruyter, 2006. p. 2430-2445.

MURRAY, S. O. Theory Groups in Science. In: MURRAY, S. O. Theory Groups and the Study of Language in North America: A social history. Amsterdam/Philadelphia: John Benjamins Publishing Company, 1994. p. 16-28.

PUTSCHKE, W. Die Dialektologie, ihr Beitrag zur historischen Sprachwissenschaft im 19. Jahrhundert und ihre Kritik am junggrammatischen Programm. In: AUROUX, S. et ali. History of the language sciences: an international handbook on the evolution of the study of language from the beginnings to the present. v. 2. Berlin/New York: Walter de Gruyter, 2001. p. 1498-1513. 
RASK, R. Undersøgelse om det gamle nordiske eller islandske Sprogs Oprindelse. Kjöbenhavn: Gyldendal, 1818.

ROBINS, R. H. A short history of linguistics. London: Routledge, 1967.

SAUSSURE, F. de. Cours de linguistique générale. Paris: Payot, 1916.

SCHLEGEL, K. W. F. von. Über die Sprache und Weisheit der Indier: ein Beitrag zur Begründung der Alterthumskunde. Heidelberg: Mohr \& Zimmer, 1808.

SCHLEICHER, A. Compendium der vergleichenden Grammatik der indogermanischen Sprachen: kurzer Abriss einer Lautlehre der indogermanischen Ursprache, des Altindischen (Sansrkit), Alteranischen (Altbaktrischen), Altgriechischen, Altitalischen (Lateinischen, Umbrischen, Oskischen), Altkeltischen (Altirischen), Altslawischen (Altbulgarischen), Litauischen und Altdeutschen (Gotischen). v. 1. Weimar: H. Boehlau, 1861.

SCHLEICHER, A. Die Deutsche Sprache. Stuttgart: G. G. Cotta'scher Verlag, 1860.

SCHWARZ, E. Goten, Nordgermanen, Angelsachsen: Studien zur Ausgliederung der germanischen Sprachen. Mit 16 Abbildungen. Bern: Francke, 1951.

STEGER, H. "Ernst Schwarz 1895-1983". Zeitschrift für Dialektologie und Linguistik, v. 51, n. 1, p. 1-5, 1984

STREITBERG, W. A. Urgermanische Grammatik. Heidelberg: Carl Winter's Universitätsbuchhandlung, 1974 [1896].

SWIGGERS, P. Modelos, Métodos y Problemas en la historiografía de la lingüística. In: ZUMBADO, C. C. (ed.). Nuevas Aportaciones a la historiografía lingüística. Actas del IV Congreso Internacional de la SEHL. La Laguna (Tenerife), 22 al 25 de octubre de 2003. v. 1. Madrid: Arco Libros, 2004. p. 113-146.

TACITUS, C. Germania. Translation with Introduction and Commentary by JB Rives, New York: Clarendon Press Oxford University Press, 1999. 
VAN COETSEM, F. C. C. Zur Entwicklung der germanischen Grundsprache. In: SCHMITT, L. E. Kurzer Grundriß der germanischen Philologie bis 1500. Band I. Sprachgeschichte. Berlin: Walter de Gruyter \& Co, 1970. p. 1-93.

VERNER, K. Eine ausnahme der ersten lautverschiebung. Zeitschrift für vergleichende Sprachforschung auf dem Gebiete der Indogermanischen Sprachen, v. 23, n. 2. H, p. 97-130, 1877. 